University of Nebraska - Lincoln

DigitalCommons@University of Nebraska - Lincoln

Faculty Publications, Department of Psychology

Psychology, Department of

$12-1973$

\title{
A Cross-Cultural Analysis of Sex Differences in the Behavior of Children Aged Three Through 11
}

\author{
Beatrice Whiting \\ Harvard Graduate School of Education \\ Carolyn P. Edwards \\ University of Nebraska-Lincoln, cedwards1@unl.edu
}

Follow this and additional works at: https://digitalcommons.unl.edu/psychfacpub

Part of the Anthropology Commons

Whiting, Beatrice and Edwards, Carolyn P., "A Cross-Cultural Analysis of Sex Differences in the Behavior of Children Aged Three Through 11" (1973). Faculty Publications, Department of Psychology. 625.

https://digitalcommons.unl.edu/psychfacpub/625

This Article is brought to you for free and open access by the Psychology, Department of at DigitalCommons@University of Nebraska - Lincoln. It has been accepted for inclusion in Faculty Publications, Department of Psychology by an authorized administrator of DigitalCommons@University of Nebraska - Lincoln. 


\title{
A Cross-Cultural Analysis of Sex Differences in the Behavior of Children Aged Three Through 11
}

\author{
Beatrice Whiting and Carolyn Pope Edwards
}

Laboratory of Human Development, Harvard Graduate School of Education

\section{Summary}

Our study suggests that (a) there are universal sex differences in the behavior of children 3-11 years of age, but the differences are not consistent nor as great as the studies of American and Western European children would suggest; (b) socialization pressure in the form of task assignment and the associated frequency of interaction with different categories of individuals - i.e., infants, adults, and peers - may well explain many of these differences; (c) aggression, perhaps especially rough and tumble play, and touching behavior seem the best candidates for biophysical genesis; (d) all of the behaviors that are characteristic of males and females seem remarkably malleable under the impact of socialization pressures, which seem to be remarkably consistent from one society to another; and (e) the difference in many of the types of behavior seems to be one of style rather than intent: i.e., seeking help ("feminine") rather than attention ("masculine"), and justifying dominance by appealing to rules ("feminine") rather than straight egoistic dominance ("masculine").

Although our findings do not speak for adolescent and adult male and female behavior, they should caution the social scientists and animal ethologists who are interested in possible evolutionary and survival theories not to underestimate the effect of learning environments. These learning environments may well be responsible for the behavior frequently attributed to the innate characteristics of male and female primates as inherited by their human descendants.

The 1973 JSP edition notes that this study was "Received in the Editorial Office, Provincetown, Massachusetts, on January 18, 1973, and given special consideration in accordance with our policy for cross-cultural research." 


\section{A. Introduction}

This paper investigates the validity of the stereotypes of sex differences as evidenced by behavior of children between the ages of three and 11 , observed in natural settings in seven different parts of the world. ${ }^{1}$

Females are frequently characterized as more dependent, passive, compliant, nurturant, responsible, and sociable than males, who in turn are characterized as more dominant, aggressive, and active. Assuming that these statements imply observable behaviors, the authors have attempted to define the stereotypes in such a way as to relate them to the categories of interactions which have been used in a series of observational studies of children in natural settings.

There are two major research issues: are these observable differences biological and genetically determined or the result of learning a society's definition of appropriate sex role behavior? To begin to answer these questions one can proceed by asking, first, whether or not the behaviors said to characterize the male and the female are present in all societies and, second, on the assumption that they are found in societies with a variety of cultures, are there associated universal sex role requirements and associated sex typed socialization pressures?

It is our assumption that sex differences reported for the United States or another Western-type culture may reflect only an idiosyncratic type of socialization. If, however, the same differences appear in societies with divergent cultures and life styles, the assumption of universality gains credence. To determine whether sex differences in behavior are biologically determined or the result of universal sex role requirements is far more difficult. Since our study does not include observations of neonates and young infants, it cannot speak to the possible influence and interaction of biological and social variables. It is possible, however, to note age changes during the 3- to 11-year age span and the presence of associated socialization pressures, and to consider the consistency of sex differences across samples of children.

\section{B. Method}

Six of the samples are the children of the Six Culture Study $(8,12)$, observed in 1954-56 by field teams who lived in communities located

1. This study is based on the field work of the six culture study, financed by the Behavioral Science Division of the Ford Foundation, and on field work in Kenya by the Child Development Research Unit, financed by the Carnegie Corporation. The analysis of the data has been made possible by a United States Public Health Grant, MH-0196. 
in Nyansongo in Kenya, Taira in Okinawa, Khalapur in India, Tarong in the Philippines, Juxtlahuaca in Mexico, and Orchard Town in New England. ${ }^{2}$ The societies were selected by the field teams on the basis of interest. They vary in complexity as reflected in occupational specialization, political structure, and settlement pattern, and in social culture. Three societies favor patrilineal extended families, the other three nuclear families. In three societies children sleep and eat with their mother, father, and siblings; in three they share intimate space with other kin. [For detailed analysis of the cultures see Whiting and Whiting (13).]

The children were all three to 11 years of age, with 12 girls and 12 boys in four of the societies, 11 girls and 11 boys in Juxtlahuaca, and eight girls and eight boys in Nyansongo. The children were observed in natural settings, most frequently in their house or yard, on an average of 17 different times for five-minute periods over a period of six to 14 months. The observations were focused on one child at a time by one of the members of the field team plus a bilingual assistant. The social interaction recorded in these paragraphs was subsequently coded at the Laboratory of Human Development at Harvard University. The code was designed to identify the instigator and instigation, if any, to the child's act and the action immediately following his act. The analysis of the 8500 interactions was done on a computer. Of the more than 70 original types of interaction coded, 12 summary types were selected for analysis. [For detailed description of methodology, see Imamura (6, pp. 3-18), Whiting (12), and Whiting and Whiting (14, chap. 3)]. The 12 behaviors are (a) Offering help-offering food, toys, tools, or general help; (b) Offering support-offering emotional support and comfort; (c) Seeking help and comfort-seeking instrumental help or emotional support; (d) Seeking attention and approval - seeking approval or either positive or negative attention; (e) Acting sociably - greeting, initiating friendly interaction, or engaging in friendly interaction; (f) Dominating - attempting to change the ongoing behavior of another to meet one's own egoistic desires; (g) Suggesting responsibly or prosocial dominance-suggesting that another change his behavior in such a way as to meet the rules of the family or other group, or serve the welfare of the group; (h) Reprimanding - criticizing another's behavior after the fact; (i) Seeking or offering physical contact-nonaggressive touching or holding; (j) Engaging in

2. Observations were gathered by Robert L. LeVine and Barbara LeVine, Thomas and Hatsumi Maretzki, Leigh Minturn, William and Corrine Nydegger, A. Kimball and Romaine Romney, and John and Ann Fischer. 
rough and tumble play - playing which includes physical contact, wrestling, and playful aggression; (k) Insulting - verbally derogating another; (l) Assaulting - attempting to injure another.

In 1968-70 a sample of 70 children between the ages of two and 10 were observed in Ngecha, a village situated 20 miles north of Nairobi in Kenya. The children were observed by students for periods of 30 minutes over the course of two years, and their behavior was recorded in running paragraphs and then coded by the observers. The code used was a revised version of the six culture code. The children between three and 10 years of age have been selected for the analysis in this paper; there were 21 girls and 18 boys aged 3-6 years, and nine girls and nine boys aged 7-10.

In order to relate the stereotypes of female and male behavior to the behavior we have observed and coded in our studies, we have attempted to define the stereotypes operationally and then selected from our codes those categories that seem best to represent the definitions. To measure the sex differences in these behaviors, we have used the proportion scores of each child for each of the relevant types of observed behavior, and computed a set of group means from those individual proportion scores. The children have been divided into groups on the basis of sex, age (3-6 years old versus 7-11 years old), and cultural sample.

Comparisons between girls and boys in each culture are based on the differences between the mean proportion scores for the behavior types. Significance levels are based on $t$-tests between the means of the sex age groups. The comparisons for the pooled samples are based on scores standardized by culture. Nyansongo and Juxtlahuaca, because of the smaller number of children (16 and 22, respectively), are slightly underrepresented when the standardized scores are pooled.

\section{Results}

1. "Dependency" (Stereotype: girls are more dependent than boys.)

There are three types of behavior which have been traditionally classified under this heading: (a) seeking help, (b) seeking attention, (c) seeking physical contact. In the six culture study, seeking for help included both asking for instrumental help-that is, requesting help in reaching a goal, asking for an object needed to reach a goal, or requesting food - and asking for comfort or reassurance. Seeking attention included bids for approval and attempts to call attention to oneself by boasting or by performing either praiseworthy or blameworthy acts with the intent of becoming the focus of another person's attention. The 
category of seeking or offering physical contact included behavior in which the child sought proximity to another, or touched, held, or clung to another.

Table 1 presents the comparisons. It can be seen that in five of the six societies girls aged 3-6 were observed to seek help more frequently than did the boys aged 3-6, and the difference between the pooled groups of younger girls and boys is significant at the .05 level. In the 7- to 11-year-old comparison, however, there is an equal split; in three societies girls were observed to seek help more than boys and in three the reverse was true.

Seeking attention is more characteristic of boys than girls. In four of the samples, boys 3-6 seek attention more frequently than do girls, but for the pooled sample of six societies there is no significant difference. Among 7- to 11-year-olds in the four societies where there are differences, boys seek attention more frequently and the difference is significant at the .05 level.

Girls were observed to seek or offer physical contact more frequently than boys. For the young group as a whole there is a marked sex difference, girls seeking or offering physical contact more frequently than boys $(p<.01)$.

In sum, the stereotype of female "dependency" holds for two of the types of behavior - seeking help and seeking or offering physical contactbut especially true of the younger age groups, there being no significant difference in these behaviors in the 7- to 11-year-olds. Seeking attention, on the other hand, as a male form of "dependency," is clearly present in the 7- to 11-year-old group, and is the only type of "dependent" behavior in which there are significant differences in the older age group.

2. "Sociability" (Stereotype: girls are more sociable than boys.)

"Sociability," which includes greeting behavior and all acts judged to have the primary intent of seeking or offering friendly interaction, is correlated with "dependent" behavior. As can be seen in Table 1, there is a slight tendency for girls to be more sociable than boys but the differences are not significant.

\section{3. "Passivity" (Stereotype: girls are passive.)}

"Passivity" is frequently associated with dependency in the stereotypes of female behavior. This concept is more difficult to operationalize. and we have accepted the definitions of Kagan and Moss (7). They list among other behavioral indices of passivity in the preschool child: (a) retreat when dominated by a sibling; (b) no reaction when goal object is lost; (c) withdrawal when blocked from goal by environmental obstacle; and (d) withdrawal from mildly noxious or potentially dangerous 


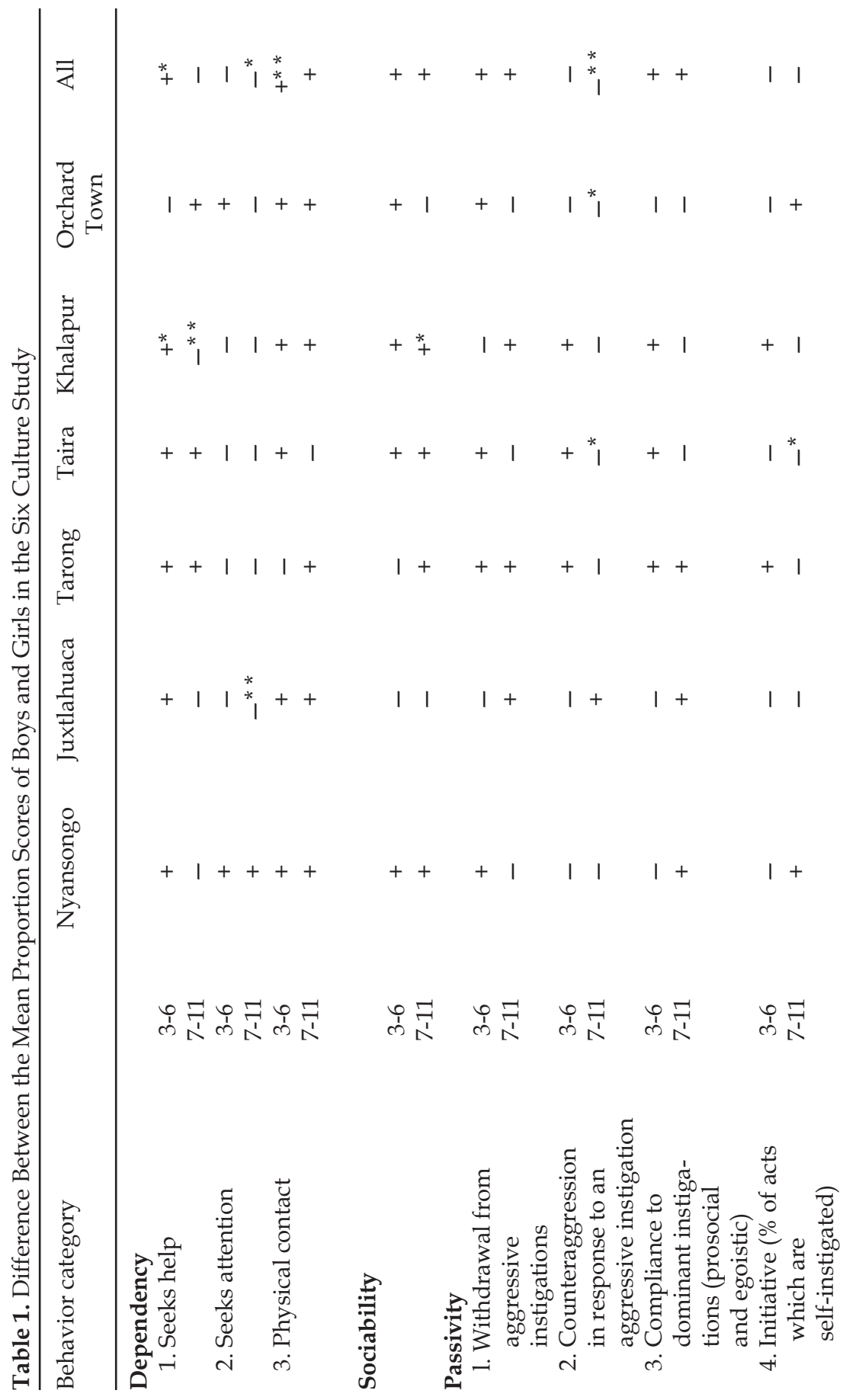




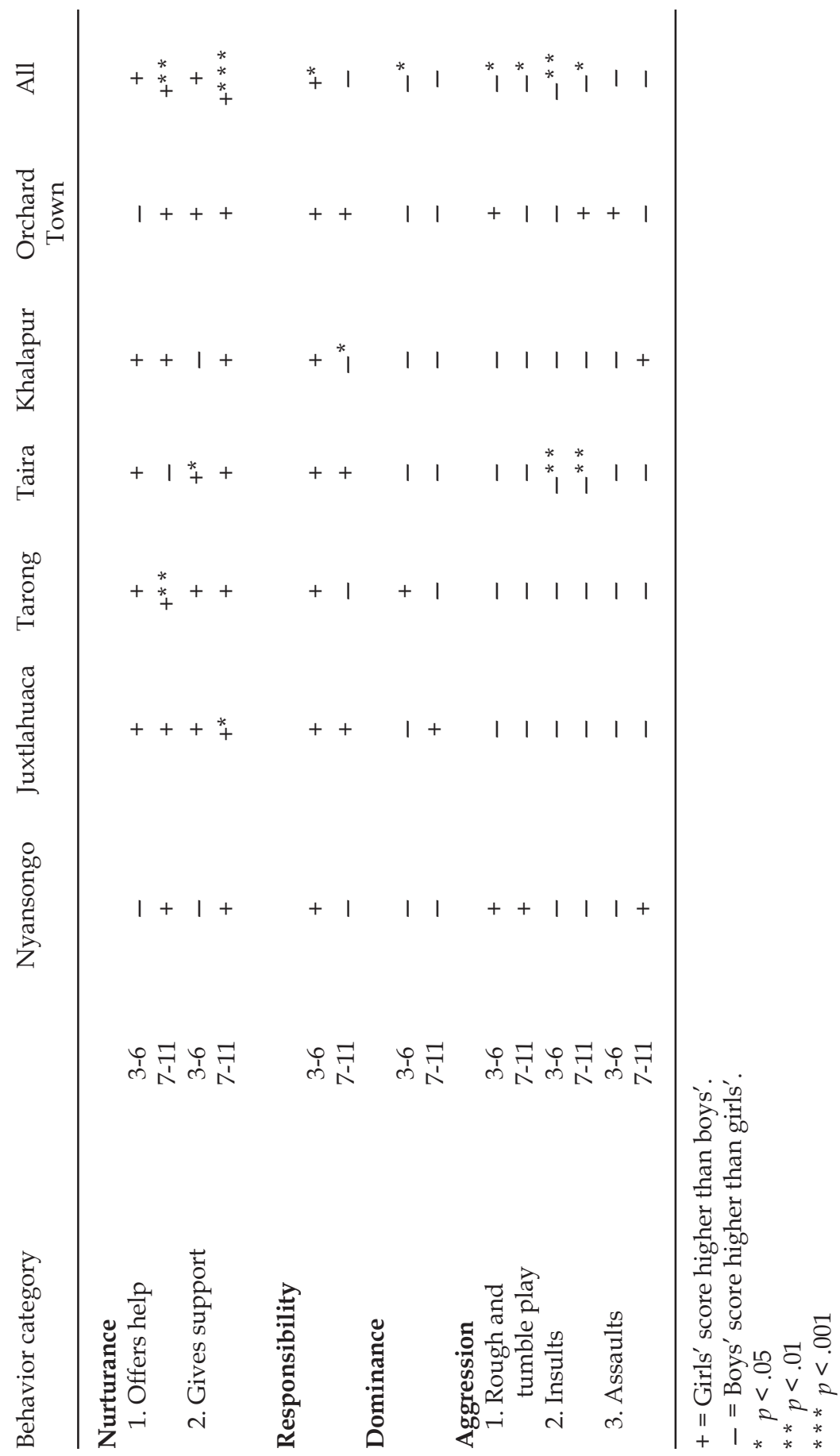


situations. During the school years, their passivity measures included (a) withdrawal from attack or social rejection, and (b) withdrawal from difficult and frustrating situations.

The six culture code included instigational situations described as encountering difficulty, being blocked, having property taken away, being challenged to competition, being insulted or physically attacked, and being dominated. In these situations, if we accept the above definition of "passivity," girls should, according to the stereotype, respond by withdrawal. Two types of instigations occur with sufficient frequency to make analysis possible: (a) aggressive instigations, including being insulted, roughed up in a playful fashion, and being physically attacked by peers; and (b) dominant instigations. We have analyzed the proportion of responses that are compliant and the proportion of those that are counteraggressive. Table 1 presents the findings. "Withdrawal" includes behavior coded as complies, hides, avoids, breaks interaction, deprecates self, and acts shy. "Counteraggression" includes playful aggression or rough and tumble play, insulting behavior, and assaulting with the judged intent of injuring another child.

It can be seen (Table 1) that there is no consistent trend in the six samples in relation to withdrawal from aggressive instigations of peers, although there is an overall tendency for girls to withdraw more frequently than boys. If one contrasts the proportion of counteraggressive responses when attacked by peers, the findings are more consistent. There is no significant difference between girls and boys in the 3-6 age group but by 7-11 the boys react proportionately and significantly more frequently with counteraggression than do the girls (Table 1).

Sex differences in compliance to prosocial and egoistically dominant instigations (Table 1) are only slightly in the direction the stereotype would predict. There is one type of compliance which is significantly different for girls and boys: namely, obedience to the mother. In the 7-11 age group girls are significantly more compliant to their mothers' commands and suggestions $(p<.05)$. However. this kind of compliance seems a much better operational measure of a variable that might be called "cooperativeness" than it does of passivity. One might interpret that the 7- to 11-year-old girls have identified with their mothers and their mothers' goals and are therefore willing to cooperate when their mothers assign tasks.

In sum, older boys respond more aggressively than girls to aggressive instigations, and there is a trend for boys to be less compliant than girls to the wishes of others. However, these differences are not as great as the literature would imply (1).

There is another dimension of behavior which might be considered 
the obverse of "passivity": namely, "initiative." As operationalized here, initiative is measured by a proportion score, the proportion of the child's acts that were judged to be self-instigated, rather than responses to the instigations of others. Table 1 presents the comparison. It can be seen that in the younger group the proportion of self-instigated acts is similar for boys and girls. In the older group boys were judged to initiate interaction proportionately more frequently than were girls, but the difference between the two groups does not reach an acceptable level of significance. What accounts for this slight difference? It could either be that girls initiate fewer acts than boys or that they receive proportionately more instigations than do boys. Girls initiate social interaction somewhat more frequently than do boys as judged by rate scores. However, girls receive proportionately more mands from others than boys. That is, other individuals interrupt and try to change the ongoing behavior of girls more than that of boys. It is this higher rate of interruptions or instigations received that makes the older girls have a slightly lower proportion of selfinstigated acts than have the boys. Perhaps this higher rate of attempts to change girls' behavior sets is related to the Western stereotype of feminine "sensitivity" or "responsiveness" and to the reports that girls have greater awareness of their immediate environment than do boys (15).

\section{4. "Nurturance" (Stereotype: girls are more nurturant than boys.)}

Table 1 presents the difference between boys and girls on two components of this behavior system. It can be seen that in the 3- to 6-yearold period there are no consistent trends across the six societies and no significant differences. By 7-11, however, girls are observed to offer help and support significantly more than boys $(p<.01$ and $<.001$, respectively). That there are no sex differences in the early age group, but rather marked increases with age, does not fit the innate differences hypothesis.

\section{5. "Responsibility" (Stereotype: girls are more responsible than boys.)}

In the six culture study any attempt to change the behavior of others with the judged intent of seeing to the welfare of the group and the maintenance of socially approved behavior has been coded as "suggests responsibly" (prosocial dominance) and distinguished from "dominance," which was defined as attempts to change the behavior of another to meet the egoistic desires of the actor. As can be seen in Table 1, in the 3- to 6-year-old group girls offered responsible suggestions more frequently than boys in all six samples, the difference significant at the .05 level of confidence. By 7-11, however, there is no difference, the boys having increased markedly. 
6. "Dominance" (Stereotype: boys are more dominant than girls.)

Egoistic dominance (Table 1), on the other hand, as the stereotype would have it, was observed more frequently in boys. The level of significance is .05 for the young group and not significant in the 7-11 sample.

7. "Aggression" (Stereotype: boys are more physically aggressive than girls; girls are more verbally aggressive.)

We have coded three types of aggression: (a) rough and rumble play, aggression which has a strong sociable component; (b) verbal aggression, primarily verbal communications judged to be motivated by the desire to derogate and insult; and (c) assaulting, physical aggression judged to be motivated by the desire to cause pain and injury. As can be seen (Table 1 ), boys were observed in rough and tumble play significantly more frequently than girls in both age groups. They were also, contrary to the stereotype, significantly more insulting than girls - the level of significance reaching .01 for the young and .05 for the older group (Table 1). Assaulting, with the intent to injure (Table 1) was not observed with great enough frequency to make any definitive statement. In five of the samples, the 3to 6-year-old boys assaulted more; by 7-11 the frequency of the behavior is roughly similar in four samples. The reader is referred back to the findings concerning responses to aggressive instigations. In sum, on all measures of aggression, boys score higher than girls but the differences are significant only in rough and tumble play and verbal aggression, and in the older group in counteraggression when attacked by peers.

\section{Discussion}

Insulting, rough and tumble play, and dominating egoistically are the most clearly "masculine" types of behavior in the 3- to 6-yearold age group, and seeking or offering physical contact, seeking help, and suggesting responsibly (or prosocial dominance) the most clearly "feminine."

The fact that body contact is involved in both rough and tumble play and touching behavior suggests that they are alternative modes of establishing cutaneous contact. One may also dichotomize two types of dominance-straight commanding (dominates), the male mode, and dominance justified by rules of appropriate behavior (suggesting responsibly), the female mode. In the other age group nurturance becomes a clearly "feminine" characteristic, and the measures of aggression distinguish the boys. Seeking attention appears to be both a "masculine" form of dependency and, in its self-arrogating aspects, a measure of competitiveness.

Although it is obviously impossible to do more than speculate about 
Table 2. Showing Significant Changes in the Mean of the Proportion Scores of the Behavior of Girls and Boys from Ages 3-6 to 7-11

\begin{tabular}{lll}
\hline Behavior & Girls & Boys \\
\hline Offers help & $+^{* *}$ & \\
Offers support & $+^{*}$ & $+{ }^{* * *}$ \\
Responsibility & $-^{* *}$ & $-^{* * *}$ \\
Seeks or offers physical contact & & $+^{*}$ \\
Proportion of self-instigated acts &
\end{tabular}

A $(+)$ indicates an increase with age; a $(-)$ indicates a decrease.

${ }^{*} p<.05$

$* * p<.01$

$* * * p<.001$

biophysical determinants of these behaviors, the sex differences that are greatest in the younger group might be considered the best candidates for sex-linked characteristics. The age trends in the behavioral systems are presented in Table 2.

Seeking and offering of physical contact, a behavior that differentiates the sexes clearly in the 3- to 6-year-old group, decreases significantly with age. One might interpret this as a decrease in the desire for physical contact, contact which may have served as a pain and anxiety reducer at the younger age and now is less frequently needed. The significant increase of nurturance and responsibility with age suggests that these are behaviors which increase with socialization pressure. Nurturance increases significantly in girls, and responsibility or prosocial dominance increases in both girls and boys. Since by 7-11 years of age there is no significant sex difference in the proportion of responsible suggestions, the significant increase for the boys may indicate that pressure for responsibility begins at an early age for girls. ${ }^{3}$ The proportionate increase of self-instigated acts of boys may reflect the fact that girls are assigned tasks that keep them closer to the house and adults, tasks and setting that are associated with more requests and demands from others.

There is evidence in our data of differential pressure on girls and boys to be nurturant. Older girls in our sample took care of children under 18 months of age more frequently than did boys $(p<.05)$, and infant care is undoubtedly one of the variables contributing to the significant increase in the proportion of offering help and support. There is also evidence

3. In Ember's study in Western Kenya and in the ongoing research in Kenya there are significant sex differences in prosocial dominance, girls scoring significantly higher than boys in the 7- to 11-year age groups. 
that more girls than boys in the younger age group are assigned responsible tasks. By the older age group, however, boys are engaged in animal husbandry, and both girls and boys are beginning to help in agricultural work. Boys feed and pasture animals significantly more frequently than girls $(p<.001)$; girls do significantly more domestic chores (cleaning $p<.001$, food preparation, cooking, and grinding $p<.001$ ) and care for siblings. The number of tasks assigned to both boys and girls increases significantly with age (8).

These sex differences in assigned work are associated with the different frequency with which boys and girls interact with various categories of people: i.e., adults, infants, and peers. Caring for infants and performing domestic chores require that girls stay in the vicinity of the house and yard and hence remain more frequently in the company of adult females. Both young and older girls interact with female adults more frequently than do boys $(p<.05$ and $<.01$, respectively), and older girls interact with infants significantly more than do boys $(p<.01)$. Herding and other animal husbandry chores take the boy away from the house. Boys interact less frequently with adults and infants and proportionately and significantly more with peers (3-4 years $p<.05 ; 7-10 p<.01)$, especially male peers.

What can be said about the consequences of this difference in type of dyadic interaction? To answer this question we analyzed the types of behavior that children direct most frequently to adults, to infants, and to child peers. These three age grades of people seem to draw different types of behavior from children, and the behavior which children direct to a given category is remarkably similar across cultures (14). The acts most frequently directed toward adults are (a) seeking help, (b) seeking or offering physical contact, (c) seeking attention, and (d) seeking friendly interaction, or "sociability" - the first two of these being "feminine" type behavior (see Table 1). When interacting with infants, children most frequently offer help, support, and sociability - the first two again "feminine" type behaviors. In contrast, when interacting with peers, sociability, rough and tumble play, and derogatory and insulting interchanges are most frequent, the last two of these "masculine" type behaviors.

Two studies in Kenya and research in progress in Guatemala confirm our deduction that girls are at home more frequently than are boys (9, 10, 11). In Kenya, Sara Nerlove working in Nyansongo and Robert and Ruth Munroe working in Vihiga made observational studies of sameaged pairs of girls and boys. At the same times each day they sought out the children's whereabouts and measured their distance from home. The girls were found to be nearer to home significantly more often than the boys. Although these findings may be interpreted to indicate that girls 
are innately more timid than boys, it seems more parsimonious to assume that they reflect socialization pressure and differential task assignment, girls being kept home to perform infant tending and domestic chores.

The question then becomes why girls are assigned domestic chores and the care of infants significantly more frequently than are boys. Is it because girls are innately better suited to such tasks or does it simply reflect a universal sex typing and a preparation of young girls for their adult roles? In all the societies we have studied, women have the major responsibility for the care of infants and for domestic chores. This is in accord with the findings of cross-cultural studies on the division of labor (3). Assigning these chores to girls rather than boys may simply reflect the early training of girls for the expected female role.

This differential socialization pressure on girls is in accord with the findings of Barry, Bacon, and Child (2) in their cross-cultural study of sex differences in socialization, based on ratings made from published ethnographic reports of societies distributed around the world. They found that girls received more pressure to be nurturant, obedient, and responsible, boys more pressure to achieve and be self-reliant. In our sample the greater frequency in the proportion of nurturant behavior, its increase with age, and the greater compliance to mothers of girls are as one would predict from the Barry, Bacon, and Child findings. As noted above the greater amount of time spent caring for infants can be interpreted as greater pressure toward nurturance. Pressure toward obedience as reported by the mothers of the six cultures is greatest in those societies that assign infant care and similarly is exerted more on girls than on boys $(13,14)$. It is also greater in those societies in which children are engaged in animal husbandry. Responsible behavior, as we have measured it, does not show significant sex differences in the six culture samples, but does in recent observational studies in Kenya (see footnote $p$. 43). However, since there is a high correlation between the Barry, Bacon, and Child ratings on pressure toward responsibility and the number of chores assigned to girls and boys as reported in the ethnographic monographs, the significant difference in the number of chores assigned to girls and boys in the 3- to 6-year-old age group is in accord with their findings. In the older group there is great variation from one society to another. The crucial variable seems to be economic; in societies with animal husbandry or agricultural work that can be assigned to boys, there is no sex difference in amount of work required of girls and boys after 7-8 years of age.

Our measures of achievement-oriented and self-reliant behavior are 
less direct, but are also in accord with the sex differences in socialization reported by Barry, Bacon, and Child. Seeking attention as we have coded it includes self-arrogation and boasting. In the older age group, as reported above, boys are proportionately significantly higher than girls in this type of behavior. If we assume that these behaviors are motivated by achievement needs, the findings are as predicted. The proportion of self-instigated acts might be considered a measure of self-reliance. There is a trend, as reported above, for boys 7-11 to be proportionately higher in acts that were not judged to be clearly instigated by the actions of others. It should be noted again here, however, that this measure may simply reflect the fact that boys are interrupted less frequently by the mands of others than are girls. The ethnographic sources make it difficult to distinguish between being allowed to do what one wishes unsupervised by others and self-reliance. ${ }^{4}$

In sum, our evidence suggests that the nature of the task assigned to girls is the best predictor of four of the five primary types of "feminine" behavior (see Table 1) since (a) the tasks require more frequent interaction with infants and adults and (b) the nature of the tasks themselves involves care of others - offering help and comfort to infants, preparing and offering food to the entire family - all work focused on the needs of others and the welfare of the family. These tasks clearly require a child to be compliant - to be willing to service the requests of others and to obey task-related instructions. Furthermore, all of these tasks require the girl to be tolerant of interruptions and demands for succorance, and require her to be constantly alert to the motivational states of others - behaviors possibly related to field dependence, a quality commonly attributed to women (15).

It is interesting to note here societal differences in "femininity" scores. Orchard Town girls, for example, score low in offering help and support and do significantly less infant care than girls in other societies.

Further insight into the possible consequences of task assignment can be gained by looking at the "masculine" and "feminine" profiles of boys who are assigned domestic chores and the care of infants. There are many societies in which young boys are required to do such work. Among these are East African societies in which women are the agriculturalists, men traditionally the pastoralists and warriors. In these societies young boys are classified with women and girls until they approach pubescence, at which time they are frequently initiated into manhood in formal rites de passage. Nyansongo, one of the six cultures, is an ex-

4. For discussion of the problem, and data on achievement and self-reliance among the !Kung Bushmen of the Khalahari, see Patricia L. Draper (4). 
ample of such a society. The women, who work four or five hours a day in the gardens, assign the care of infants to a designated older sibling and the tending of the cooking fire and the washing of utensils to the same or some other child of the family. Although others prefer girl nurses, it is not considered inappropriate to delegate the responsibility to a boy if there is no female of the proper age-in this case under 10 years of age, since older girls are either in school or helping in agricultural work.

Our evidence suggests that requiring boys to tend babies and perform domestic chores reduces sex differences in the mean proportion scores of "masculine" and "feminine" behavior in two of these East African societies. In Nyansongo half of the boys aged five and over took care of infants and half helped with domestic chores. When one contrasts the mean proportion scores of the boys and girls, the magnitude of the sex differences is smaller than in any of the six societies with the exception of Orchard Town, which will be discussed later. Nyansongo boys scored higher than would be predicted on offering help and offering support, young boys scoring higher than young girls on both types of behavior. Nyansongo girls are aberrantly high in rough and tumble play, younger girls in assaulting, and boys retreat from aggressive attacks from peers as frequently as do girls. The comparisons are similar in Ngecha, our other East African sample. In the Ngecha sample, the older boys offer help and support somewhat more frequently than do the girls $(p<$ $.22)$, the younger boys seek sociability significantly more than do the girls $(p<.05)$, the older girls seek attention slightly more frequently than do the boys $(p<.23)$, and the girls of both ages were observed in rough and tumble play as frequently as the boys.

A more detailed analysis of the effect of assigning "feminine" tasks to boys has been presented by Carol Baldwin Ember (5). In 1968 when she was working in Oyugis in Western Kenya, by a fluke of sex ratio there were an unusually large number of households in which there was no girl of the appropriate age to care for an infant sibling, and hence there was quite a large sample of boys who were acting as nurses and doing domestic chores. Using this unusual opportunity Carol Ember undertook an observational study of these boys. She compared them to a matched sample of boys who were not responsible for "feminine" chores, as well as to a sample of girls. She used a code similar to that used in the six culture study. Her observations were made when the children were not working.

Her findings based on a linear regression of the means for the three groups - boys who did little child tending or domestic chores which kept them inside the homestead, boys who did many such tasks, and girls- 
show significant differences between the three samples. Boys high on feminine work had behavior profiles that were more "feminine" than boys who did not perform such work. They were more responsible (prosocially dominant), less aggressive (including assaulting and insulting), less dependent (including seeking help, support, attention, information, and material goods), ${ }^{5}$ and less egoistically dominant (including dominating, reprimanding, and prohibiting action egoistically (all differences significant at the .01 level). The differences were not great, however, when Ember compared boys who were and who were not assigned "feminine" chores which took them outside the homestead: i.e., carrying water, fetching wood, digging root crops, picking vegetables, and going to the market to mill flour. Her data do not show the predicted differences in nurturant behavior.

In sum, in societies where boys take care of infants, cook, and perform other domestic chores, there are fewer sex differences between boys and girls, and this decrease is due primarily to the decrease in "masculine" behavior in boys; boys are less egoistically dominant, score proportionately lower in some forms of aggression, seek attention proportionately less frequently, and score higher on suggesting responsibly. On the other hand, the 3- to 6-year-old girls in these societies are high on assaulting and miscellaneous aggression, and both younger and older girls score low on sociability (14).

Although there are no samples of girls in any of the six cultures who do "masculine" type tasks, the girls of Orchard Town, New England, as mentioned above, do very little infant care. Since most New England families consist of two children averaging around two years apart in age, and since there are no courtyard cousins, young nieces, nephews. or halfsiblings as in extended and polygynous families, there is little opportunity for Orchard Town girls to care for infants except as paid baby sitters. In general, however, Orchard Town mothers do not hire baby sitters under 11 years of age. Orchard Town girls are also more strongly committed to education and may aspire to jobs that are considered appropriate to both sexes. Their work in school is practically identical with that of boys. It is interesting, therefore, to see how this sample of U.S. girls who have been observed in natural settings fits the predicted patterns on the behaviors which we have found to be significantly different between boys and girls in the pooled samples. As in Nyansongo, the magnitude of the differences is small. The direction of the insignificant differences

5. It is unfortunate that dependency as operationally defined by Ember included both the masculine and feminine modes. 
is as expected with one exception, the young girls scoring higher than the boys in the proportion of attention seeking, a "masculine" type behavior. They also score higher than any other sample of girls on this type of behavior-behavior which in general is higher among the children of the more complex societies (Orchard Town, Khalapur, and Taira) where schooling and achievement are more highly valued (14). It is a type of behavior which, when directed toward adults, is frequently motivated by a desire for approval and, as discussed above, when directed toward peers may have affiliation or self-arrogation as its goal. It is a frequent behavior in New England classrooms.

As noted above, the Orchard Town girls score the lowest of the samples of girls on offering help and support, "feminine" traits, and have one of the lowest percentages of interaction with infants.

In sum, in both the East African societies where "feminine" work is assigned to boys and in Orchard Town, New England, where less "feminine" work is assigned to girls and where there is less difference in the daily routine of boys and girls, the behavior of girls and boys does not show as great differences as in other societies.

\section{References}

1. Bardwick, J. M. Psychology of Women: A Study of Biocultural Conflicts. New York: Harper \& Row, 1971.

2. Barry, H., III, Bacon, M. K., \& Child, I. L. A cross-cultural survey of some sex differences in socialization. J. Abn.\& Soc. Psychol., 55:327-332, 1957.

3. D'Andrade, R. G. Sex differences and cultural institutions. In E. E. Maccoby, ed., The Development of Sex Differences. Stanford, Calif.: Stanford University Press, 1966.

4. Draper. P. L. !Kung bushman childhood: A review of the Barry, Child, and Bacon hypothesis regarding the relation of child training practices to subsistence economy. Paper presented at the annual meetings of the American Anthropological Association, New York, November, 1971.

5. Ember, C. R. The effect of feminine task assignment on the social behavior of boys. Ethos, 1973, in press.

6. Imamura, S. Mother and Blind Child: The Influence of Child Rearing Practices on the Behavior of Preschool Blind Children. New York: Amer. Found. for Blind, 1965.

7. Kagan, J. \& Moss, H. A. Birth to Maturity. New York: Wiley, 1962.

8. Minturn, L. \& Lambert, W. W. Mothers of Six Cultures: Antecedents of Child Rearing. New York: Wiley, 1964.

9. Munroe, R. L. \& Munroe, R. H. Effect of environmental experience on spatial ability in an East African society. J. Soc. Psychol., 83:15-22, 1971. 
10. Nerlove, S. B. Private communication, 1971.

11. Nerlove. S. B., Munroe, R. H., \& Munroe, R. L. Effect of environmental experience on spatial ability: A replication. J. Soc. Psychol., 84:3-10, 1971.

12. Whiting, B. B., ed., Six Cultures: Studies of Child Rearing. New York: Wiley, 1963.

13. Whiting, B. B. \& Whiting, J.W.M. Task assignment and personality: A consideration of the effect of herding on boys. In W. W. Lambert \& R. Weisbrod, eds., Comparative Perspectives on Social Psychology. Boston: Little, Brown, 1971.

14. Whiting, J.W.M., Whiting, B. B., \& Longabaugh, B. Children of Six Cultures. In press.

15. Witkin, H. A., Dyk, R. B., Faterson, H. R., Goodenough, D. R., \& Karp, S. A. Psychological Differentiation. New York: Wiley, 1962. 